\title{
Tatuaje: ficción interactiva de una pesquisa hipermedial
}

\section{Tatuaje: the Interactive Fiction of a Hypermedial Inquest}

\author{
Andrea Medina Téllez Girón \\ Universidad Autónoma del Estado de Morelos \\ amedinatg@gmail.com
}

RESUMEN: Las nuevas apuestas en la narrativa electrónica se estructuran bajo trayectos hipertextuales que vinculan una gran variedad de recursos, una imagen estática, un video, un audio, en los que se organiza la trama. Tal es el caso de la ficción electrónica Tatuaje (2015) de Rodolfo Jiménez Morales. La narración tiene una estructura policiaca, lo que permite el diseño hipertextual para que el lector-usuario siga desde la perspectiva del investigador, Rolo Martínez, su experiencia en la solución del suceso. Si bien el detective no está obligado a resolver ni a conocer el caso al modo de Holmes, sí debe comprender las pistas de las que éste se compone. Estas piezas son los diferentes recursos presentados en la narrativa a manera de indicios: audios, correos electrónicos, Ilamadas telefónicas y mensajes de texto. Este ensayo tiene el objetivo de mostrar desde el marco de interactividad el nivel de exposición e involucramiento del detective-lector con sus pistas en relación con su proceso de codificación-decodificación del caso-mundo. El propio usuario atestigua, a manera de reto, su habilidad en dar respuesta al caso, estructurar la secuencia de los eventos y poder explicarse a sí mismo su rol en un mundo hipertextual. Para ello es necesario revisar primero los conceptos de hipertexto, hipermedia e hipervínculo; segundo, los niveles de interactividad y tercero el análisis de la ficción electrónica.
PALABRAS Clave:

ficción interactiva;

hipermedia;

interactividad;

lectura.

ABSTRACT: The new bets in the electronic narrative are structured under hypertext paths that link a wide variety of resources, such as a static image, a video, an audio, in which the plot is framed. That is the case with the electronic fiction Tatuaje (2015) by 
KEYWORDS: Interactive Fiction; Hypermedia; Interactivity; the Reader.
Rodolfo Jiménez Morales. The narrative has a detective structure, which allows the hypertextual design for the reader-user to follow, from the perspective of Rolo Martínez, the investigator, his experience in solving the case. Although Martinez is not obliged to solve all the cases or have absolute knowledge as Holmes, he is to fit the clues in during or after the case. These clues come from different resources along the narrative: audios, emails, phone calls, text messages that are not resolved in the explanation of the case. This essay aims to show from the interactivity frame, the level of exposure and detective-reader involvement with the clues in relation to his coding-decoding process of the world-case. The user witnesses, in a challenging manner, his ability to solve the case, to structure the sequence of events and to explain himself his role in a hypertext world. For this, the essay reviews, first the concept of hypertext, hypermedia, and hyperlink; second, the levels of interactivity; and third the analysis of the electronic fiction.

recepción: 4 abril 2018.

aceptación: 20 octubre 2018.

Tal vez los lectores asiduos de Borges fueron quienes primero tuvieron una idea clara de los alcances del Internet: el aleph, los laberintos, las bibliotecas infinitas de libros finitos encontrarían en la realidad virtual una materialidad cotidiana. Las nuevas apuestas en la narrativa electrónica se estructuran bajo trayectos hipervinculares que enlazan una gran variedad de recursos, desde una imagen estática, un video, un audio, en los que se entreteje la trama. Tal es el caso de la ficción electrónica Tatuaje (2015) de Rodolfo Jiménez Morales. Este nuevo tipo de aventuras literarias tiende a atraer un gran público, por el halo de interactividad que rodea a la narración y debido a los "viajes" textuales que realiza el lector oprimiendo enlaces que lo trasladan a otros espacios en la red. El lector siente que el texto electrónico es mucho más interactivo que el impreso porque percibe que realiza más acciones apretando botones en su pantalla que cambiando la página de un libro. Esta nota, sin embargo, no se ubica en la confrontación de lo impreso versus lo digital, sino en los diferentes niveles de interactividad que conforman la ficción electrónica; de ahí que nuestra 
primera pregunta sea: ¿bajo qué supuesto de interactividad se estructura Tatuaje y por qué?

Para responder, en primer término se abordarán los términos hipermedia, hipertexto e hipervínculo; en segundo lugar, se arribará a lo que se entiende aquí por interactividad y se definirán los niveles que la conforman. Con base en este marco se analizará, por último, la ficción electrónica.

\section{Hipermedia: conectando espacios}

Ted Nelson (1967) introdujo dos términos claves: hipertexto e hipermedia; empleó el concepto hipertexto para referirse a los pedazos o lexías interconectadas que caracterizaban la estructura de un texto digital (18); diferenció de manera tajante el hipertexto del texto analógico, del que no es ni su continuación ni su doble. En esta misma línea se encuentra Glazier (2013), para quien el hipertexto es aquel que puede ser buscado entre miles de documentos; es transmisible de manera rápida; no posee un tamaño físico; puede ser manipulado (69); es multisecuencial (Bolter: 10) y no-lineal; rompe las jerarquías textuales y transforma, además, el concepto de autoría, ya que coloca al lector en el mismo nivel que al autor (Landow: 84), puesto que construye sus caminos de lectura por medio de las conexiones entre textos disponibles (Slatin: 158). Sin embargo, Carey Jewitt (2009) hace notar que el hipertexto también se encuentra en medios analógicos como la Biblia e incluso el periódico. Entonces, si el hipertexto no es exclusivo de lo digital, ¿dónde está la diferencia?

La distinción entre un hipertexto analógico y uno digital está precisamente en el medio que lo contiene. Este tipo de problemática se debe a que el texto posee varias connotaciones, ya sea la de artefacto (Ryan 2011), la del lenguaje que se emplea para representar la estructura del artefacto (Ciccoricco 2007) o el medio básico, es decir, las formas elementales que comparten los medios (Elleström 2010). Esto significa que el hipertexto como artefacto es diferente al texto analógico, puesto que está ligado al medio que lo potencializa; en tanto estructura, la web nació para ser hipertextual, es su forma de organización; en cuanto al medio básico, éste es una forma que comparten los medios analógicos y digitales. Ahora bien, sobre la estructura digital, Nelson Ilamó hipermedia a la particulari- 
dad de representación porque produce, "[the] best read at an interactive screen" $^{1}$ (2) y "[that] provide pathways to help active reading" ${ }^{2}$ (18). Enslin llamó hipermedia a la unión de diferentes recursos tales como: texto e imagen, imagen e imagen, texto y video, etc. (262). ¿Entonces la hipermedia es consecuencia del hipertexto?

Lev Manovich introdujo un tercer término, hipervínculo: "In hipermedia, the multimedia elements making a document are connected through hyperlinks. Thus the elements and the structure are independent of each other-rather than hard-wired together, as in traditional media" ${ }^{3}$ (38). Conviene, entonces, entender el hipertexto como organización textual que se desvincula de los enlaces que interconectan sus partes (hipervínculo) y de los diferentes recursos que conecta (hipermedia).

Glazier (2013) diferencia entre los hipervínculos que componen la red y los que conforman el mundo delimitado de un hiperlibro; sin embargo, estos últimos muchas veces relacionan recursos que no dependen de la base de datos proporcionada por el hiperlibro. Por ejemplo, cuando los personajes de Tatuaje tienen cuentas en Facebook desde las que conversan con sus lectores; o poseen listas de reproducción musical en Spotify o videos en Youtube. Esta es la razón por la que Serge Bouchardon denomina a este tipo de productos de ficción, narración interactiva: "La tendance actuelle est aux hypermédias animés en ligne qui exploitent conjointement l'affichage dynamique du texte et la dimension multimédia et mettent l'accent sur l'interactivité avec un lecteur"4 (17); el lector cuenta con una variedad de opciones que se extienden en un amplio número de textos, sea que estén contenidos en el hiperlibro, la hiperficción, o se extiendan a otras plataformas; es decir el flujo de los hipervínculos no sólo conecta recursos sino espacios. La hipermedia por lo tanto se define por los espacios enlazados que dan forma a una narración interactiva.

1 Hay una mejor lectura en una pantalla interactiva (la traducción libre es mía; en adelante T. de A.).

2 Proporciona senderos para ayudar a la lectura activa (T. de A.).

3 En hipermedia, los elementos multimedia que forman un documento se conectan a través de hipervínculos. Por lo tanto, los elementos y la estructura son independientes entre sí, en lugar de conectarse en conjunto, como en los medios tradicionales (T. de A.).

4 La tendencia actual es que la hipermedia en línea aprovecha la visualización dinámica del texto y la multimedia para enfatizar la interactividad con un lector (T. de A.). 
Marie-Laure Ryan (2004) distingue cuatro tipos de espacios: físico, discursivo, material y contenedor. El espacio físico es el del mundo representado en la ficción; el discursivo equivale a la arquitectura del texto: narrativas enriquecidas, arborescentes, multifocales, topográficas, autogenerativas, multimodales, transmedia (Favre 2000); el espacio material es el ocupado por los signos del texto; el contenedor es el espacio en el que la ficción y el lector se encuentran, y donde un personaje adquiere una sustancia "real" como la del lector. En este flujo de espacios se genera la interactividad.

En las siguientes líneas Ilamaré hipervínculo a los enlaces entre un recurso y otro; hipertexto, a un tipo de organización textual, e hipermedia al conjunto de diferentes espacios que conforman un producto específico.

\section{La interactividad}

A pesar de que la interactividad remite a la interacción entre dos o más personas, no es un sinónimo, ya que "interactivity is best (though no exclusively) understood as a perceptual variable that involves communication mediated by technology"5 (Bucy: 376). La definición de Bucy es importante, primero, porque nos ayudará a ubicar dónde está la interactividad en la comunicación mediada; y segundo, porque se considera una variable de percepción, lo cual apunta a la subjetividad en tanto experiencia de un usuario.

Hay principalmente tres maneras de entender la interactividad como comunicación mediada. La primera considera la interactividad propia de la tecnología por sus cualidades de velocidad, rango y mapeo (Steuer 1992); este tipo de perspectiva limita la interactividad al medio, cuando en realidad provee condiciones para generar la interactividad. La segunda, ubica la interactividad en la percepción del usuario frente al medio (Rogers et al. 1998), lo que la hace depender de las representaciones internas que el usuario tenga del medio y menoscaba la interactividad a la que invita el medio. La tercera explica la interactividad como un proceso de comunica-

5 La interactividad es la mejor (aunque no exclusiva) forma de llamar a una variable perceptual que involucra la comunicación mediada por la tecnología (T. de A.). 
ción, en el que existe involucramiento y retroalimentación. Si es así, ¿por qué no considerar la interacción como característica de la tecnología? La tecnología está programada para reaccionar, incluso los asistentes digitales se basan en un proceso de acción por parte de un usuario y reacción del programa. Entonces, si la interacción depende de un sujeto, ¿por qué no considerarla inherente a él? Rafaeli explica que el sujeto no es el único involucrado en la interacción e identifica los siguientes actores: persona a persona (interacción social), usuario a medio, usuario a contenido y medio a medio (83). Kiousis toma la estafeta y define interactividad como: "the degree to which a communication technology can create a mediated environment in which participants can communicate, both synchronously and asynchronously, and participate in reciprocal message exchanges" ${ }^{\prime \prime}$ (372).

Sohn (2011) propone tres dimensiones de interactividad: sensorial (sensory), semántica (semantic) y conductual (behavorial). Estos niveles corresponden al medio, el usuario y el proceso; ningún tipo de interactividad se puede generar si uno de ellos falta.

En la dimensión sensorial, la percepción es un elemento clave; la información que se adquiere del ambiente mediante los sentidos es transformada en objetos de experiencia, eventos, sonidos, gustos (Sohn: 6). Mientras más viva sea la percepción del objeto, mayor será su potencial interactivo.

La dimensión semántica implica evaluar las características y la relevancia de la interpretación asociada al objeto. Es decir, el sujeto sopesa qué tan reconocido es por los otros participantes de la interacción de acuerdo con la calidad de sus mensajes o la retroalimentación que se produzca.

La dimensión conductual se refiere a las acciones que la persona realiza y dan cuenta de su comportamiento ante el medio (control, responsabilidad, elecciones complejas, velocidad de respuesta): "How we perceive and experience technology is dependent in the preexsting structure and process of our mind" ${ }^{\prime 7}$ (11). Es decir, estas dimensiones dependen de la

${ }^{6}$ El grado en que una tecnología de comunicación puede crear un entorno mediado en el que los participantes pueden comunicarse, tanto de forma sincrónica como asincrónica, y participar en intercambios recíprocos de mensajes (T. de A.).

7 La manera en que percibimos y experimentamos la tecnología depende de la estructura y el proceso preexistentes de nuestra mente (T. de A.). 


\begin{tabular}{llll}
\hline & \multicolumn{1}{c}{ Atributos } & \multicolumn{1}{c}{ Interacción } & \multicolumn{1}{c}{ Experiencia } \\
\hline Nivel sensorial & $\begin{array}{l}\text { Estimulantes } \\
\text { sensoriales }\end{array}$ & Sensación & $\begin{array}{l}\text { Percepción } \\
\text { de objeto/acción }\end{array}$ \\
Nivel semántico & $\begin{array}{l}\text { Información/carac- } \\
\text { terísticas retóricas }\end{array}$ & $\begin{array}{l}\text { Interpretación } \\
\text { de significados }\end{array}$ & $\begin{array}{l}\text { Reconocimiento } \\
\text { recíproco }\end{array}$ \\
& $\begin{array}{l}\text { Posibilidades } \\
\text { latentes de acción }\end{array}$ & $\begin{array}{l}\text { Secuencia de } \\
\text { acción/reacción }\end{array}$ & $\begin{array}{l}\text { Comportamiento } \\
\text { conductual } \\
\text { percibido }\end{array}$ \\
\hline
\end{tabular}

Modelo sintáctico de interacción. Tomado de Sohn: 12.

interactividad esperada y percibida. La interactividad que se espera puede ser o no compatible con lo que el sujeto percibe en un contexto comunicativo.

Estos niveles de interactividad encuentran un eco en los tipos propuestos por Marie-Laure Ryan (2011): periférica, discursiva, creativa, generativa. La interactividad periférica es la inherente al medio, que equivale a la percepción que el sujeto se hace de él (nivel sensorial). La interactividad discursiva es la que afecta la narrativa; se compone por los materiales que constituyen la historia. Este tipo se corresponde con el nivel semántico de Sohn, en tanto que el mensaje es estructurado por el autor y reestructurado por el usuario. La interactividad creativa corresponde a las variaciones en una historia predefinida; en este nivel el usuario tiene un papel en la historia y se le dota de agencia. La interactividad generativa implica la colaboración del usuario en la construcción de la historia. Estos dos últimos niveles corresponden a lo que Sohn Ilama comportamiento.

\section{Vericuetos hipertextuales}

En esta sección se analizarán los niveles de interactividad de Tatuaje. Siguiendo la propuesta de Sohn, se pueden identificar tres dimensiones o niveles en la ficción que nos ocupa: en el nivel sensorial se encuentra, en efecto, un tatuaje; en el nivel semántico, se puede hablar de vericuetos hipertextuales; y en el conductual, encontramos al personaje principal. 
Tatuaje se ambienta en la Ciudad de México en una época contemporánea a su publicación. Es una narrativa con estructura policiaca que gira en torno al propio detective, Rolo Martínez, en un periodo de cuatro días. Él es contactado por un hombre llamado Jabamuel para entregar un sobre a Melquíades Orozco, un brujo; éste tatúa a Rolo, extrañamente. A partir de ese momento se le presentan diferentes personas que son acechadas por Jabamuel. Rolo encuentra a Melquíades por segunda vez y tiene una revelación que es incapaz de explicar.

En el nivel sensorial, la percepción es un elemento clave, es el proceso en el que la información se adquiere por los sentidos y da paso a experiencias, de acuerdo con Sohn. En este sentido, la novela posee dos planos de interactividad: el del lector y el de la ficción que vive Rolo. Sobre el lector, ya desde la presentación de la novela se le interpela: "En esta historia eres más que un lector, eres un cómplice". El hecho de que se narre en primera persona y que la perspectiva de los eventos sea siempre la de Rolo crea un efecto de identificación, particularmente a través de los videos o cuando Rolo se ve el tatuaje. Otro elemento que hace que el lector perciba la novela como interactiva está en la solicitud de un nombre de usuario, e-mail, password y confirmación; requisitos necesarios para que el lector pueda retomar su lectura donde la dejó. Otros elementos más que influyen en la percepción de interactividad son los siguientes: la pantalla se divide en dos áreas, de un lado está la bitácora y el explorador que pertenecen a Rolo y del otro lado los recursos disponibles adicionalmente: imágenes, mail, mapas, mensajes, archivos y Ilamadas. Estos recursos estimulan multisensorialmente al lector (por los sonidos, los íconos, el diseño de la interfaz) lo cual hace percibir la novela como altamente interactiva. Sin embargo, la interacción está en un plano de mera reacción, el programa solicita una acción y el lector la realiza para seguir avanzando; es decir, es una novela de interactividad reactiva.

En el plano de la ficción, hay una revitalización del poder creador de la palabra y de la función del símbolo que une, bajo su representación, contrarios. El hipertexto para Rolo queda reducido a las búsquedas que hace en el Explorador, en el archivo de Pereira y en su correo electrónico. Los elementos que estimulan sensorialmente a los personajes giran alrededor de los símbolos que los capturan en pesadillas (algunas de ellas se 
transforman en masacres). Por medio de los sueños Jabamuel accede al inconsciente de los personajes y hace que experimenten el mundo onírico que trata de materializarse, como el caso de los pacientes de Vannesa García.

La aparición del lenguaje enochiano desata un caos que apunta a Rolo. El tatuaje trazado por Melquíades señala al protagonista de la historia; el símbolo marcado en la piel de Rolo hace que surtan efecto en él las palabras proferidas por Jabamuel; por eso el tatuaje le arde en la pesadilla y fuera de ella. Es imprescindible, pues, comprender la función de esta marca dentro de la novela ya que da respuesta a la interactividad de los personajes, a la gran intervención del Mago desde su Universidad Invisible y a la extraña visita de Mariluz. He identificado cuatro funciones que cumple el tatuaje.

La primera es que, al marcar a Rolo como un mensajero, hace que el detective cumpla también la función de medio. Una de las razones para elegir a Rolo consiste en que él, a diferencia de Melquíades, es un poeta. Rolo puede articular las canciones que Melquíades jamás aprendió al lado de María Sabina; y Rolo es el medio por el que Jabamuel puede incidir en la realidad humana. Su perfil de golem nos muestra por qué Rolo tiene una baja interactividad con el caso, pues él no va tras las pistas, éstas le llegan a través de Mariluz y Perea: "En tu caso puede que no te convirtieran en golem, pero por algo te eligieron". Su perfil de fisgón hace dudar de su capacidad como detective profesional.

Segunda función: Rolo no hace averiguaciones sobre su tatuaje; le basta la opinión del policía, quien lo describe como un diablito; no obstante, Mariluz asegura que es una representación de Hermes. En realidad, el tatuaje de Rolo es una mónada jeroglífica con que se representaba el origen del cosmos y proviene del libro Monas Hieroglyphica de John Dee, un ocultista inglés del siglo xvı. En este sentido, el hecho de que Rolo sea su portador es un indicio de que Jabamuel quería instaurar un nuevo inicio para la humanidad en el que Rolo sería una especie de Malinche.

Tercera función: Rolo comprende en su poema que existe otra realidad, que comienza y se desprende de este mundo. La composición fechada el 30 de agosto parece invocar los sucesos con fecha de octubre. Parece una variable causal el hecho de que las personas a las que Jabamuel se les ha 
aparecido tengan un trabajo relacionado con el uso de la palabra: narradores, periodistas, editores.

Cuarta función: el tatuaje posee un sustrato rico de tradiciones próximas a los chamanes (María Sabina) y al lenguaje esotérico-místico enochiano, que se emplea para atraer otro mundo a éste. William Burroughs es citado varias veces a propósito de este sustrato, y se alude a él cuando Rolo recibe un anónimo: "La realidad no existe, el lenguaje es un virus". Sin embargo, este préstamo no corresponde con los supuestos del escritor beat. El Mago Ilama virus a la realidad porque se expande y porque contagia a las personas que ven el mensaje de Jabamuel; en cambio, Burroughs creía que el lenguaje humano era un virus que contaminaba el cerebro e impedía ver la realidad. Si fuera así, ¿cómo es que la enfermedad se deja reconocer a sí misma si todos estamos infectados? Jabamuel, un ser superior, no despierta lo inefable en los personajes, sino el sentimiento de terror, desesperación, angustia; revela un mudo descarnado en el que las personas están indefensas ante sus miedos, como escribe Vannesa García. Jabamuel es una parodia de Emanuel, el niño anunciado que habita con la humanidad; pero Jabamuel, a la manera de Samael, está en contra de ella, aunque el temor a Samael ha casi desaparecido, hay otros miedos que han surgido; Jabamuel evoca el nombre del lenguaje de programación, Java, y la terminación -muel, el miedo moderno de un lenguaje incomprensible. Jabamuel adquiere el sustrato de leyenda cibernética del "señor de los sueños" unido al miedo prehistórico de aquello incomprensible que lo abarca todo. El tatuaje es, pues, un elemento sensorial de los personajes, el cual se une al rostro de Jabamuel.

En el nivel semántico, el tatuaje sirve de frontera, puesto que el lector no queda incluido en esta dimensión de la interactividad; el sistema sólo reconoce a Rolo, y el lector queda como testigo de la narración sin ser reconocido por ninguno de los personajes. Rolo se pierde en un laberinto de textos, de información. Él fue identificado y hallado por Jabamuel y Mariluz. Gracias a la pista que ella le proporciona, Rolo reconoce en su cliente Jabamuel al ser de las pesadillas que los acosa. Pese a ello, Rolo no saca ninguna interpretación al respecto, se queda con la información de Perea, con la que le llega por "arte de magia" o mediante un reconocimiento de datos, pero no logra articular lo que sabe en una hipótesis. 
Rolo se muestra incapaz de darle una dirección a sus experiencias y a las búsquedas mínimas que realiza. En este sentido, el lector puede pensar en "La muerte y la brújula", de Borges; aunque Lönroth sigue las pistas y deduce la manera de operar del asesino, no alcanza a prever lo que ocurrirá al final; así va a Triste-Le-Roy a encontrar su propia muerte. La diferencia con Rolo es que éste desconoce el trasfondo que hay en las pistas: "yo sé que pasó, algo... ojalá pudiera explicarlo". El gran fisgón no es apto para fisgonear su propia vida y desmantelar los resortes que operan sobre él, confiesa: "Nunca he sabido interpretar sueños, no sé leer las señales, si es que las hay". Los papeles se invierten, Rolo no puede decir quién es quién en el caso; por contraparte, Mariluz, Jabamuel, el Mago, Perea, ellos saben quiénes son, lo que están haciendo y el papel de Rolo dentro del caso.

La imagen del laberinto hipertextual se encuentra en el video del sueño y la revelación y entre ambas se observa una secuencia. La pesadilla es un lugar laberíntico en el que hay puertas cerradas y espacios vacíos por los que Rolo entra a un no-lugar; el camino desaparece y él se deja guiar por la oscuridad; en los ascensos que parecen descensos termina por encontrar a Jabamuel tras unas rejas bisbiseando algo en lengua incomprensible, lo que genera dolor en el pecho de Rolo. El video de la revelación parece ser una continuación de la pesadilla, puesto que inicia con Rolo viéndose el tatuaje y termina con los seres principales que lo tocan, y le muestran el libro sagrado que seguramente vio María Sabina: un libro sin palabras "cuyo contenido pude leer sin necesidad de conocer el lenguaje en el que está inscrito". A pesar de que Rolo tiene permiso de leer el libro, parece que no consigue salir del laberinto; el video termina con una fusión a blancos que sugiere una elevación sobre la situación, pero no resulta en la revelación del misterio. Rolo continúa en el mismo estado, no experimenta ningún cambio de perspectiva, de cosmovisión o de vida. Al final de la narración está sentado en el Olimpo, bar, masticando pensamientos derrotistas.

Jabamuel es un ser principal que toma forma humana y arácnida; así teje un laberinto, construye una red que produce el fracaso de Melquíades para adquirir fuerza en el mundo material. Jabamuel trenza una cota de sueños entre los escritores que participan en el blog para hacer germinar su nicho corporal (publicación de Iliana Vargas). Jabamuel es, pues, una 


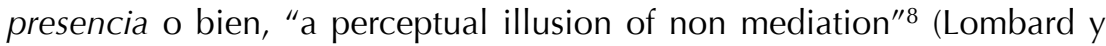
Snyder-Duch: 58). Jabamuel es el miedo a la no mediación, a vivir una realidad sin medios, una realidad descarnada y cruda que cada vez se hace más extraña e incompatible. Acostumbrados a la red, al olvido de las jerarquías textuales y a las relaciones asimétricas, Jabamuel es el lenguaje que programa los miedos, que permea las conciencias de las personas, emplea un código incomprensible para imponer una estructura interconectada de soñadores con una misma presencia que los oprime y afecta la manera de leer y comprender su mundo.

De acuerdo con Ryan, ya citada en el primer apartado, los hipervínculos unen espacios. El espacio físico de la ficción es la Ciudad de México, otro espacio es el de las pesadillas en el que Jabamuel visita a sus soñadores. El espacio discursivo, en tanto arquitectura textual se ve enriquecido por el espacio material o por la interfaz que el autor creó para esta narración. Este espacio hipertextual que el autor ha diseñado pone en espejo al lector, ya que el mundo de éste también es hipertextual. Como ocurre con la red que teje "Cara de Luna" para Rolo, parece que el lector también termina inmerso en hipervínculos que asocian el mundo ficcional de Tatuaje con sitios no ficcionales dentro de la red, como el de Wikipedia o los reportajes sobre María Sabina.

Rolo apenas interactúa con los recursos hipertextuales por medio de la red y con el mundo que le rodea; sigue las pistas pero no se adelanta al plan de Jabamuel ni lo desmantela.

En el nivel del comportamiento, la interactividad de Rolo resulta escasa, como ocurre con la del lector. A pesar de que Rolo posee cuentas de Facebook e Instagram, lo que permite las interacciones simétricas, los lectores, hasta el momento en que se redactó esta nota, no participaban en esas plataformas, pues no se encontraron comentarios sobre el caso ni publicaciones que remitieran a la narración. Estos espacios se encuentran abandonados, aunque sean altamente eficaces para la interactividad, pues el lector tiene la opción de construir el final, de interactuar con los personajes o bien podría aprovechar los recursos de lectura hipermediales presentados por la novela. Por lo tanto, la lectura activa de esta ficción descansa en

8 Ilusión perceptiva de no mediación (T. de A.). 
el uso posible de los hipervínculos, no en el papel del lector, que sobre todo se deja guiar, sin desempeñarse como un co-creador. Así, como no se produce transmisión ni recepción de mensajes, la interactividad es baja.

Rolo es un personaje opaco: adquiere, por proximidad, características de otros para constituir su identidad. Perea es el investigador que Rolo no alcanza a ser; es él quien encuentra el "Libro del leguaje sagrado" de Melquíades y le da abundante información a Rolo; de no ser por Perea, incluso no habría una trama policiaca.

Como poseedor del tatuaje, Rolo está marcado por el conocimiento de las fuerzas ocultas y de la manipulación del mundo real. Es por ello que comparte la posición de Melquíades: ambos son mediocres, uno por no tener el don de aprender los cantos de su tía Sabina y el otro porque migra de una profesión a otra sin brillar en ninguna: pasa de periodista a poeta, a detective. Rolo y Melquíades se complementan, por ser uno el cantor y el otro por ser quien posee el conocimiento de lo oculto; sin embargo, Rolo no asume este conocimiento.

El tatuaje de Rolo puede tomarse como un índice de la capacidad para metamorfosearse: puesto que ingresa al libro, se convierte en palabra. A pesar de esto, no se aprecia ningún cambio en él; es un ser opaco, un golem, un mensajero. Quizá por eso el poema que le regala el barman de Kerouac le hace tanto sentido; él es incapaz de pronunciar una palabra para crear su mundo. Es sólo un transmisor y nunca un héroe: para él en la vida real "los misterios no siempre se resuelven, el héroe no siempre es un héroe ni se queda con la muchacha guapa. El villano tal vez no fuera villano, no lo sé. Todo lo que quería en ese momento era emborracharme y volver a ser un fisgón solitario capaz de pagar la renta". Rolo no decodifica su realidad como lo haría un personaje de Poe. Si puede considerársele un elegido es sólo porque está marcado pero de ningún modo porque actúe sobre la realidad.

Hace falta anotar algunos cabos sueltos. Primero, si Rolo sabe quién escribe el blog de "alguienlohavisto", ¿por qué no se contacta con Ruy Feben? Segundo, si es un detective, ¿por qué no intenta descubrir la variable que comparten las personas a quienes se les ha aparecido Jabamuel? Tercero, cuando Perea le entrega el archivo, la ficha de información señala que Melquíades ha vivido en la Ciudad de México, pero Rolo nunca 
indaga su dirección. Cuarto, la fecha de nacimiento de Melquíades, de acuerdo con la ficha, es el 16 de mayo; ¿por qué en la bitácora de Rolo aparece viernes 28? ¿Y por qué los correos electrónicos están fechados en octubre? Quinto, si el Mago es quien envía a Mariluz y anda tras la pista de Rolo para hacerlo traer a su Universidad Invisible y poder conocerlo, entonces, ¿cómo crea un antivirus que destruye a Jabamuel sin ayuda de Rolo? Sexto, ¿por qué la policía anda tras Melquíades si es protegido por personas poderosas?

\section{Conclusión}

En la primera parte de esta nota se discutió la diferencia entre hipertexto, en tanto un tipo de organización textual; el hipervínculo se definió como un enlace entre diferentes tipos de recursos; y el término hipermedia se reservó para el conjunto de espacios vinculados por enlaces. El hipervínculo establece una ruta lectora que lleva a experimentar el texto como interactivo, ya que requiere de una acción por parte del usuario. Las producciones de ficción de este tipo se llaman narraciones o ficciones interactivas y pueden ser de distintas clases, de acuerdo con el nivel de interactividad e involucramiento del lector.

En la segunda parte, se habló de la interactividad como un proceso comunicativo que no reside totalmente en el medio ni en las experiencias del sujeto, sino que en el proceso engloba ambos elementos dentro de un contexto. Se retomaron las dimensiones de interactividad propuestas por Sohn: sensorial, semántica y conductual para establecer que en la narración interactiva Tatuaje los estímulos del lector (la dimensión sensorial) dependen de los botones, hipervínculos y recursos de audio, video, documentos, etc.; como la interacción se mantiene gracias a la perspectiva del protagonista, la experiencia sólo es reactiva. En la ficción, los estímulos que reciben los personajes principalmente dependen del tatuaje de Rolo y de la experiencia de las pesadillas.

Como figura detectivesca, Rolo depende de la información que recibe para poder dominar el laberinto hipertextual; así, la experiencia narrativa, en su dimensión semántica, se centra únicamente en Rolo. 
En la dimensión conductual las acciones son tan sólo latentes; la interacción y exposición del lector y el protagonista son bajas.

Que una novela recurra a la hipermedia no significa que sea altamente interactiva. Tatuaje es el ejemplo de una interactividad a nivel sensorial reactiva porque el lector continúa siendo un receptor en una relación asimétrica, en la que no interviene en la interpretación ni en la acción. Rolo Díaz o Rolo Martínez es el reflejo del lector actual que encuentra asequible una gran variedad de recursos en poco tiempo, sin el esfuerzo de antaño; pero ante la diversidad y abundancia puede mostrarse incapaz de comprender la realidad que lo rodea. Rolo, como el lector, se pierde en los vericuetos hipermedia; puede estar ante grandes revelaciones, pero es incapaz de comprender el peso que tienen en su realidad próxima. Rolo, el mensajero de los seres supremos, el elegido, termina en un bar preocupándose por pagar la renta. Si los conceptos de elección o libertad, si las deidades, lo sagrado o lo místico fueron el centro de la actividad y la reflexión en el pasado, ahora se redefinen bajo el tamiz de la red, del hipertexto.

Las manifestaciones sociales quizá hallarán su nicho en change.org, pero lo sagrado e inefable todavía busca el suyo en la transparencia del medio, en la realidad virtual, en el mundo sinestésico y el terror de vivir desconectado de la red. Rolo Díaz es un personaje en medio de relaciones que ocurren en un mundo sin tinta, sin sangre y sin lectores virtuales capaces de descifrarlo.

\section{Bibliografía}

Bolter, JAY DAVID. Writing Space: Computers, Hypertext, and the Remediation of Print. USA: Routledge, 2001.

BouChARDON, Serge. "Du rècit hypertextual au rècit interactif", en Revue de la BNF. France: Bibliothèque Nationale de France, 42 (2012): 13-20. Artículo en línea disponible en: <https://www.cairn.info/revue-de-la-bibliotheque-nationalede-france-2012-3-page-13.html > [consultado el 30 de julio de 2018].

BuCY, P. ERIK. "Interactivity in Society: Locating an Elusive Concept", en The Information Society 2.0. United Kingdom: Taylor \& Francis Group. Vol. 20, núm. 5 (2004): 373-383. Artículo en línea disponible en: <https://www.tandfonline. com/doi/abs/10.1080/01972240490508063>.

CICCORICCO, DAVID. Reading Network Fiction. USA: University Alabama Press, 2007. 
ELLESTRÖM, LARS. Media borders, Multimodality and Intermediality. USA: Springer, 2010.

Enslin, Astrid. "Hipertextuality", en The Johns Hopkins Guide to Digital Media. Emerson Lori, Marie-Laure Ryan. Baltimore: John Hopkins University Press, 2013. 258-266.

FAVRE, JULIEN. "Fiction interactive: quels formats?", en Dossiers de l'audiovisuel. Quels contenus pour Internet? Paris: Institut National de L'audiovisuel, 92 (julio-agosto 2000): 53-54.

Glazier, Loss Pequeno. Digital Poetics: Hipertext, Visual-Kinetic text and Writing in Programable Media. USA: University Alabama Press, 2013.

JeWItT, CAREY. Technology, Literacy, Learning. A multimodal approach. United Kingdom: Routledge, 2009.

Jiménez MORAles, Rodolfo. Tatuaje (2015). Novela en línea disponible en: <http:// tatuaje.centroculturadigital.mx> [consultada el 20 de octubre de 2017].

KIOUSIS, SPIRO. "Interactivity: a concept explication", en New Media \& Society. Thousand Oaks. Vol. 4, núm. 3 (septiembre 2002): 355-383. Artículo en línea disponible en:<https://journals.sagepub.com/doi/10.1177/146144480200400303> [consultado el 20 de septiembre de 2017].

Landow, George. Hypertext 3.0: Critical Theory and New Media in an Era of Globalization. Baltimore: The Johns Hopkins University Press, 2006.

Lombard, M y JenNifer SNyder-DuCH. "Interactive advertising and presence: A framework", en Journal of Interactive Advertising. United Kingdom: Taylor \& Francis. Vol. 1, núm. 2 (2001): 56-65. Artículo en línea disponible en: <https://www.tandfonline.com/doi/abs/10.1080/15252019.2001.10722051> [consultado el 3 de octubre de 2017].

MANOVICH, LEV. The Language of New Media. USA: Massachussets Institute of Technology, 2001.

Nelson, TheOdOR. Literary Machines. uSA: Mindful Press, 1967.

RAFAelI, S. y Yaron Ariel. "Assessing interactivity in computer-mediated research", en Adam N. Joinson, Katelyn Y. A. McKenna, Tom Postmes Ulf-Dietrich Reips (eds.). Oxford Handbook of Internet Psychology. Oxford University Press, 2012. Artículo en línea disponible en: <http://www.oxfordhandbooks.com/view/10.1093/ oxfordhb/9780199561803.001.0001/oxfordhb-9780199561803-e-006> [consultado el 29 de septiembre de 2017].

Rogers, Yvonne, Aldrich, Frances y SCAIFE, Mike. "Getting to grips with interactivity: helping teachers assess the educational value of CD-Roms", en British Journal of Educational Technology. Vol. 29, núm. 4 (1998): 321-332.

Ryan, Marie-Laure. "Cyberspace, Cybertext, Cybermaps". Brown University, 2004. Artículo en línea disponibleen: <http://www.dichtung-digital.org/2004/1-Ryan. html $>$ [consultado el 20 de julio de 2018].

Ryan, Marie-Laure. "The interactive onion. Layers of user participation in Digital Narrative Texts", en Ruth, Page, E.Thomas, Bronwen (eds.). New Narratives: Stories and Storytelling in the Digital Age. University of Nebraska Press, 2011. 35-62.

Slatin, JOHN. "Reading Hypertext: Order and Coherence in a New Medium", en Hypermedia and Literary Studies. Paul Delany, George Landow (eds). USA: MIT Press, 1991. 153-170. 
Sohn, Dongroung. "Anatomy of interaction experience: Distinguishing sensory, semantic and behavorial dimensions of interactivity", en New Media \& Society. Sage Journals. Vol. 13, núm. 8 (2011): 1320-1335. Artículo en línea disponible en: <https://journals.sagepub.com/doi/abs/10.1177/1461444811405806> [consultado el 19 de septiembre de 2017].

Steuer, John. "Defining Virtual Reality: Dimensions Determining Telepresence", en Journal of Communication. Vol. 4, núm. 2 (diciembre de 1992): 73-93.

Andrea MEDina TÉlLEZ Girón

Estudiante de doctorado en la Universidad Autónoma del Estado de Morelos en la línea de investigación de tecnologías y modos de aprendizaje. Maestra en Letras Modernas por la Universidad Iberoamericana. Ha impartido clases a nivel superior en universidad privadas y medio superior en escuelas públicas. 